R. L. Olsen, J. A. Hayden, C. E. Alford, R. L. Kochen, J. R. Stevens Rockwell International Energy Systems Group Rocky Flats Plant Golden, Colorado 80401 Under Contract DE-AC04-76DP03533

for United States Department of Energy
This report was prepared as an account of work sponsored by the United States Govemment Neither the United States nor the United States Departmer the Energy, nor any of their emplates, Department of contractors, subcontraciors, or their, nor any of their any warranty express or in their employees, makes liability or exprisility for the accursumes any legal or usefulness of auy information, accuracy, completeness process disclosed, or represents that its us, product or infringe privately owned nighs.

\title{
INTRODUCTION
}

\section{Soil Contamination}

During the last few years, many articles have appeared in newspapers and journals concerning radioactive contamination around Rocky Flats.1,2 The amount of plutonium in the soil has been of particular interest. The Draft Environmental Impact Statement ${ }^{3}$ on Rocky Flats lists the yearly alpha releases from the Plant since it was opened in 1952. The largest release was from "contaminated oil leakage." In 1958, a drum storage area was estahlished on virgin ground just inside the present-day east gate to Rocky Flats. The drums contained cutting oil and carbon tetrachloride contaminated with plutonium and uranium cuttings from the machining of nuclear weapon components. Deterioration of and leakage from the drums was first obscrved in 1964. This leakage resulted in the soil being contaminated. In January of 1967, the last drums were added to the area. Shortly after this time, drum removal commenced and continued until all drums were removed by January 1968. The level of contamination in the soil was measured at this time. The results showed levels from 2,000 to $300,000 \mathrm{dpm} / 100 \mathrm{~cm}^{2}$ and penetration depths of 3 to $20 \mathrm{~cm}$. In April of 1969, a gravel cover of approximately $15 \mathrm{~cm}$ was applied and by July the area had been covered with a $7.5 \mathrm{~cm}$ asphalt pad. 


\section{DISCLAIMER}

This report was prepared as an account of work sponsored by an agency of the United States Government. Neither the United States Government nor any agency Thereof, nor any of their employees, makes any warranty, express or implied, or assumes any legal liability or responsibility for the accuracy, completeness, or usefulness of any information, apparatus, product, or process disclosed, or represents that its use would not infringe privately owned rights. Reference herein to any specific commercial product, process, or service by trade name, trademark, manufacturer, or otherwise does not necessarily constitute or imply its endorsement, recommendation, or favoring by the United States Government or any agency thereof. The views and opinions of authors expressed herein do not necessarily state or reflect those of the United States Government or any agency thereof. 


\section{DISCLAIMER}

Portions of this document may be illegible in electronic image products. Images are produced from the best available original document. 


\section{Form of Contamination}

The plutonium at this site was originally in the form of plutonium metal from the machining process. In the environment, the plutonium metal oxidized to $\mathrm{PuO}_{2}$. Actual $\mathrm{PuO}_{2}$ particles have been identisied in the cutting oil used for machining. The average diameter of these particles is 0.2 microns. Besides the particulate form of the plutonium in the soil, there exists also a dispersed form. The dispersed form of the plutonium will pass through a 0.01 micron pore filter. Up to 50\% of the total contamination may have been in this form. As the barrels sat outside, hydrochloric acid was probably generated. This acid reacted with the plutonium giving a dissolved plutonium species. The exact nature of the dispersed form is not known. However, the plutonium is probably absorbed onto the clay or organic material in the soil or precipitated as $\mathrm{Fe}_{2} \mathrm{O}_{3}-\mathrm{PuO}_{2}$ coatings on the mineral surfaces. When evaluating potential decontamination processes, both the particulate and dispersed forms of the plutonium must be considered.

\section{Guidelines}

The EPA has issued a guideline for maximum levels of radioactivity in soil. The level of $200 \mathrm{mCi} / \mathrm{km}^{2}$ for plutonium in soil was calculated from a maximum permissible air concentration of respirable size dust assuming reasonable values for the soil density and mass loading. This is approximately 10 to $15 \mathrm{pCi} / \mathrm{g}$ or 20 to $30 \mathrm{dpm} / \mathrm{g}$. Because of instrumental limitation during rapid survey of soil, DOE has indicated that soil containing less than $1,000 \mathrm{dpm} / \mathrm{g}$ does not have to be excavated, but can be left in place. However, if the soil is removed, it cannot be returned to the ground unless it is less than $30 \mathrm{dpm} / \mathrm{g}$. Therefore, any process employed to decontaminate soil must reduce the level of contamination to below $30 \mathrm{dpm} / \mathrm{g}$.

\section{Alternative Solutions}

The pad area is $113 \mathrm{~m}$ wide and $120 \mathrm{~m}$ long. Approximately 80 to 90 grams of plutonium are dispersed in $2 \times 10^{7} \mathrm{~kg}$ of soil beneath the pad. Water transport has not been observed under the pad since monitoring at the four corners began in 1969. Therefore, the contaminated soil is effectively isolated from the environment. In spite of this apparent stability, there was concern about long-term diffusion of plutonium from the site. cost estimates to remove and ship the contaminated material were made and alternative solutions investigated. The present-day a.lternatives are as follows: 
1) Stabilize in place.

2) Remove and transport all of the soil to a permanent disposal site.

3) Decontaminate.

The first alternative has been eliminated as a viable longterm solution because of the concern about diffusion.. The second alternative has been used at Rocky Flats extensively during the last few years on small areas of contaminated soil. The decontamination alternative offers improved socio-political impact and will reduce any potential long-term effect. That is, the soil is actually being "cleaned up," not just moved to another site. Moreover, the decontamination option is also more economical. The actual cost to dig, package, and ship soil to a permanent disposal site in Nevada is $\$ 255$ per $1,000 \mathrm{~kg}$. Projected costs to decontaminate $90 \%$ of the soil and ship $10 \%$ is $\$ 1.23$ per $1,000 \mathrm{~kg}$. This second cost estimate includes manpower and chemicals, but excludes the initial capital cost of the processing facility. This cost was excluded because the process facility will be used only two years at Rocky flats and then moved to other sites. The cost would increase proportionally if the decontamination was less than $90 \%$ effective.

Because of the projected savings of the decontamination alternative, a soils decontamination project was initiated. The objective of the project is to develop and demonstrate decontamination processes to concentrate or remove actinides associated with contaminated soils at Rocky Flats. The bulk of the soil would be returned to its natural environment, while the remaining small fraction would be packaged for shipment. Approximately nine man-years of effort were expended in FY-1979. The ultimate goal of the project is the consiruction of a. $\$ 5-7$ million mobile process facility.

\section{EXPERTMENTAL AND RESULTS}

\section{Laboratory Studies}

Several soil conditions exist at Rocky flats that are advantageous to decontamination processes:

1) The soil is very rocky, 2) the contamination exists on the surface of the minerals, and 3) the surface-contaminated soil contains only approximately $20 \%$ clay and organic matter. A typical soil profile in the Rocky Flats area contains three distinct horizons. The dark top soil layer is usually 15 to $25 \mathrm{~cm}$ thick. This horizon is usually followed by a rocky zone rich in Iimonite and hematite-coated minerals. This zone runs from 25 to $40 \mathrm{~cm}$ in depth, but is missing under the paci. Finally, a layer of tan bentonite clay is 
observed. This layer varies in thickness and is located at a depth of 40 to $75 \mathrm{~cm}$ below the surface. The plutonium contamination does not penetrate the clay layer. The total cover over the Rocky flats area consists of this rocky alluvial material.

Because of this rocky material, a physical scrubbing process is very effective. Four such processes have been investigated:

1) Wet screening at high $\mathrm{pH}$.

2) Attrition scrubbing with calgon $(\mathbb{R}$. at elevated $\mathrm{pH}$.

3) Attrition scrubbing at low $\mathrm{pH}$.

4) Cationic flotation of clays.

Wet screening. The first process is a simple wet screening process with the $\mathrm{pH}$ adjusted to 11 with $\mathrm{NaOH}$. Both the $\mathrm{Na}^{+}$and the $\mathrm{OH}^{-}$ions help disperse the clay particles." In fact, a colloidal suspension is formed. This suspension is due to the hydroxide ions attaching to the surface of the clay, creating negatively charged particles which repel each other. Details of one run are shown in Figure 1. The +35 mesh (greater than 420 micron) fraction of soil is decontaminated to less than $30 \mathrm{dpm} / \mathrm{g}$. Typically, this material represents 60 to $70 \mathrm{wt} \%$ of the soil and can be returned to the environment. The remaining 30 to 40 wt $\&$ is radioactive and would be packaged and shipped for permanent disposal.

Attrition Scrubbing at $\mathrm{High} \mathrm{pH}$. Calgon solutions at high pH also effectively cecontaminate soil. The soil is scrubbed in a rotary-type attrition scrubber (jar mill) four times. The fine material is decanted each time. In a typical experiment, $1 \mathrm{~kg}$ of soil is scrubbed with $1,000 \mathrm{ml}$ of solution for 5 to 7 minutes. The fines are decanted removing most of the contamination. The scrub is repeated three more times with $250 \mathrm{ml}$ of solution each time. A total of $99.9 \%$ of the activity is removed with the fine fraction. This fraction represents about 20 wt $\%$ of the total soil. The remaining 80 wt 8 is below the EPA guideline and can be returned to the environment.

Two processes are taking place that decontaminate the soil. one process is the physical grinding action due to the large rocks present in the soil. The tumbling action in the jar mill actually grinds away the outer surface of the particles. The second process is the dispersion of the clay and the fines being generated by the high $\mathrm{pH}$ Calgon solution. The two processes work together to decontaminate the soil.

If an additional blender-type scrub is incorporated in the process, the amount of material decontaminated can be increased. The material less than $4 \mathrm{~mm}$ is scrubbed at $800 \mathrm{rpm}$ in a special 


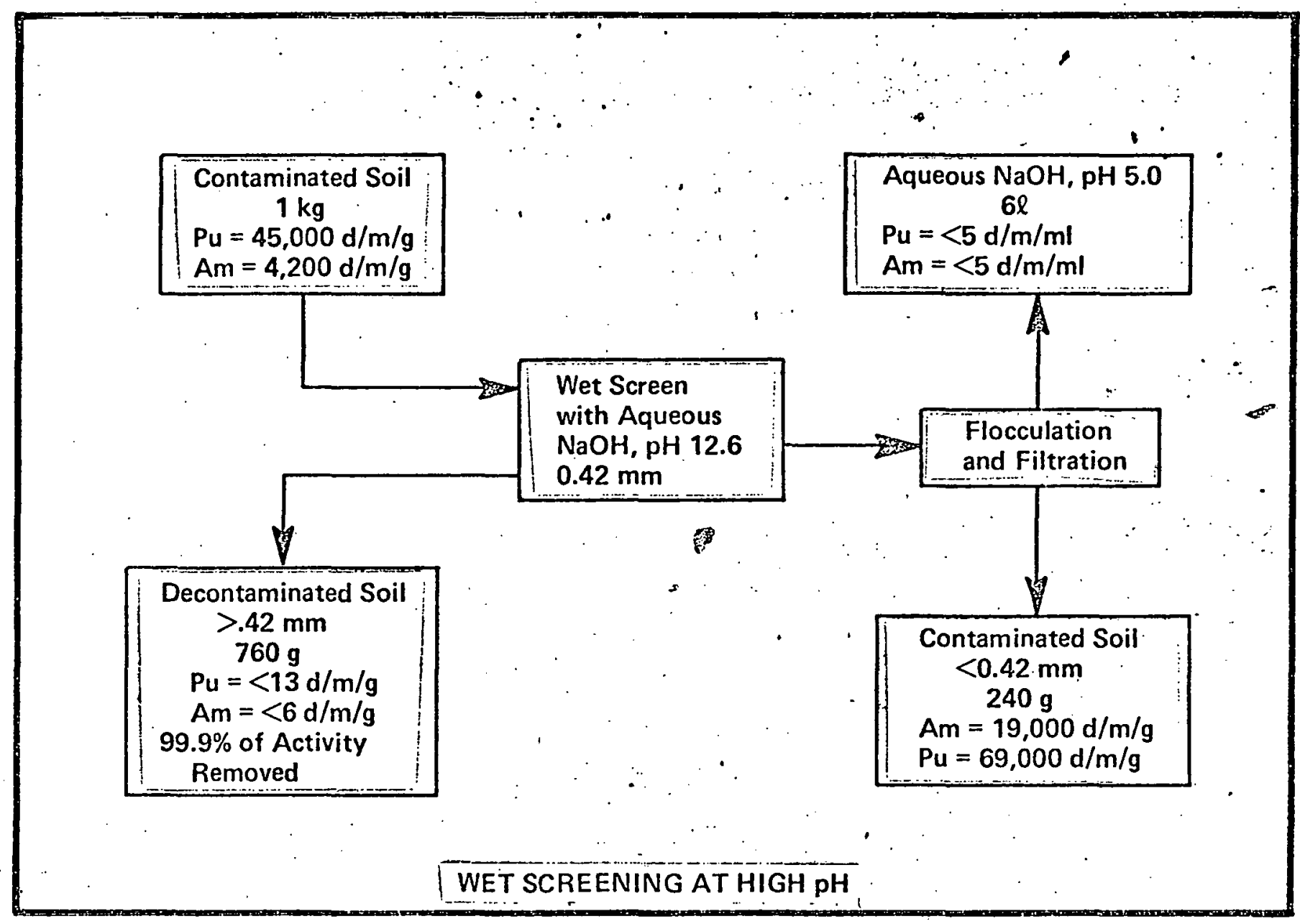


container. This process imparts a high shear to the particles thus liberating more of the contamination into the fine fraction: The outer surfaces of the particles are also effectively removed.

Attrition Scrubbing at Low pH. Attrition scrubbing at low $\mathrm{pH}$ employs the same process as attrition scrubbing at high $\mathrm{pH}$ except that the scrubbing solution has been changed. An aqueous solution of $2 \% \mathrm{HNO}_{3}, 0.2 \% \mathrm{HF}, 2 \%$ pine oil, and $5 \%$ Calgon is most effective. The soil is scrubbed five times in the rotary-type scrubber: three times for seven minutes each and two times for one minute. After each wash, the fines are removed. The first wash removes $88.1 \%$ of the contamination, while the second, third, and fourth washes remove $7.1,3.5$, and $1.3 \%$ of the contamination respectively. A typical experiment decontaminated $84 \%$ of the soil to less than $5 \mathrm{dpm} / \mathrm{g}$. Originally, the soil contained $45,000 \mathrm{dpm} / \mathrm{g}$.

The acid attacks the surface of minerals and aids in the grinding process. Smaller sized particles are scrubbed effectively, thereby increasing the total amount of soil that is decontaminated. Using the acid scrub solution, approximately $2 \%$ of the decontaminated material is less than 200 mesh ( 74 microns) in size.

When an acid solution is used in scrubbing, no colloidal suspension is observed. However, some of the plutonium does dissolve. This plutonium must be removed from the water so it can be recycled. The removal can be accomplished by: 1) coprecipitation of the plutonium with $\mathrm{BaSO}_{4}$ or $\mathrm{Fe}(\mathrm{OH})_{3}$, or 2) adsorption by the hydroxide form of an anion exchange column. The ion exchange process is actually a precipitation of $\mathrm{Pu}(\mathrm{OH})_{4}$ on the resin in the column.

In some experiments, the larger material $(-5+35$ mesh) did not decontaminate to an acceptable level. However, by removing the magnetic fraction, the level was reduced to less than $30 \mathrm{dpm} / \mathrm{g}$. Close examination of the magnetic fraction revealed that all the contamination was contained in several small particles. These particles could have been pieces of the rusted drums.

Cationic Flotation. The fourth decontamination process takes advantage of the anionic surface of the clay particles. A cationic flotation agent such as an amine can be used to float the clay material in a conventional flotation process. By adding a quartz suppressor, the soil can be scrubbed at a high speed (greater than 1,000 rpm). Usually at such high speeds, the larger rocks are abraded extensively, causing an increase in the weight of the fine fraction. However, with the addition of the suppressor, these abraded particles will not float with the clay fraction. Further research would be needed on this method. 
Methods to extract the plutonium from the fine clay fraction are also being considered. These processes include leaching with ceric solutions in $\mathrm{HNO}_{3}$ and contact leaching with $\mathrm{HF}, \mathrm{HNO}_{3}$, and $\mathrm{Na}_{2} \mathrm{CO}_{3}$ solutions.

\section{$\underline{\text { Pilot plant Studies }}$}

The attrition scrubbing process at high $\mathrm{pH}$ is the most feasible process to scale up. The process flow diagram shown in Figure 2 was generated based on the high $\mathrm{pH}$ scrub. A feed rate of 10 tons per hour $(9,000 \mathrm{~kg} / \mathrm{hr})$ was selected for the full scale facility. The soil would pass through a 4-inch $(10 \mathrm{~cm})$ grizzly to eliminate the large rocks. The material would then enter a rotary Trommel scrubber. A screen attached to the end of the scrubber would separate out the material greater than $1 / 4$ inch ( $6 \mathrm{~mm}$ ). This fraction would be sent to landfill because it would contain less than $30 \mathrm{dpm} / \mathrm{g}$. The fines material would then be washed and screened at 35 mesh $(0.420 \mathrm{~mm})$. The material greater than $0.420 \mathrm{~mm}$ would be sent to landfill. The fines fraction would be further processed using three stages of 1 -inch $(2.5 \mathrm{~cm})$ liquid cyclones. The cyclones would separate the soils fractions at $10 \mu \mathrm{m}$. The smaller fraction would be packaged for shipment while the larger fraction would be decontaminated by further treatment. This process would provide a weight reduction of $88 \%$. As the final plant must be mobile and self-contained, a water recycle system is shown on the diagram.

Results. Pilot Plant testing was performed on "cold" material fed at a rate of approximately $275 \mathrm{~kg} / \mathrm{hr}$. Testing on "hot" material was accomplished at a rate of $70 \mathrm{~kg} / \mathrm{hr}$. The mass balance for the cold test circuit is shown in Table I. Calculations showed that 4-inch $(10 \mathrm{~cm})$ cyclones were better suited for the desired flow rates. Three stages of cyclones were employed to separate the soil at $10 \mu \mathrm{m}$. However, as indicated in Table I, the underflow (the desired decontaminated product) still contained $17 \%$ of the minus 10 micron material.

If the cut is made at 400 mesh ( 37 micron) after two stages of cyclones, the underflow contains only $1.6 \%$ and $0.4 \%$ of the -38 micron and -10 micron material respectively. These numbers represent $0.36 \%$ and $0.086 \%$ respectively of the total mass. This cut is made very efficientiy. Therefore, a separation could be made at 400 mesh ( 37 microns) instead of 10 microns. The weight reduction is lowered to $83.8 \%$.

FUTURE WORK

Modifications

If the clrcult were modified to cut at 100 mesh (149 microns), 
$500 \mathrm{gpm}$

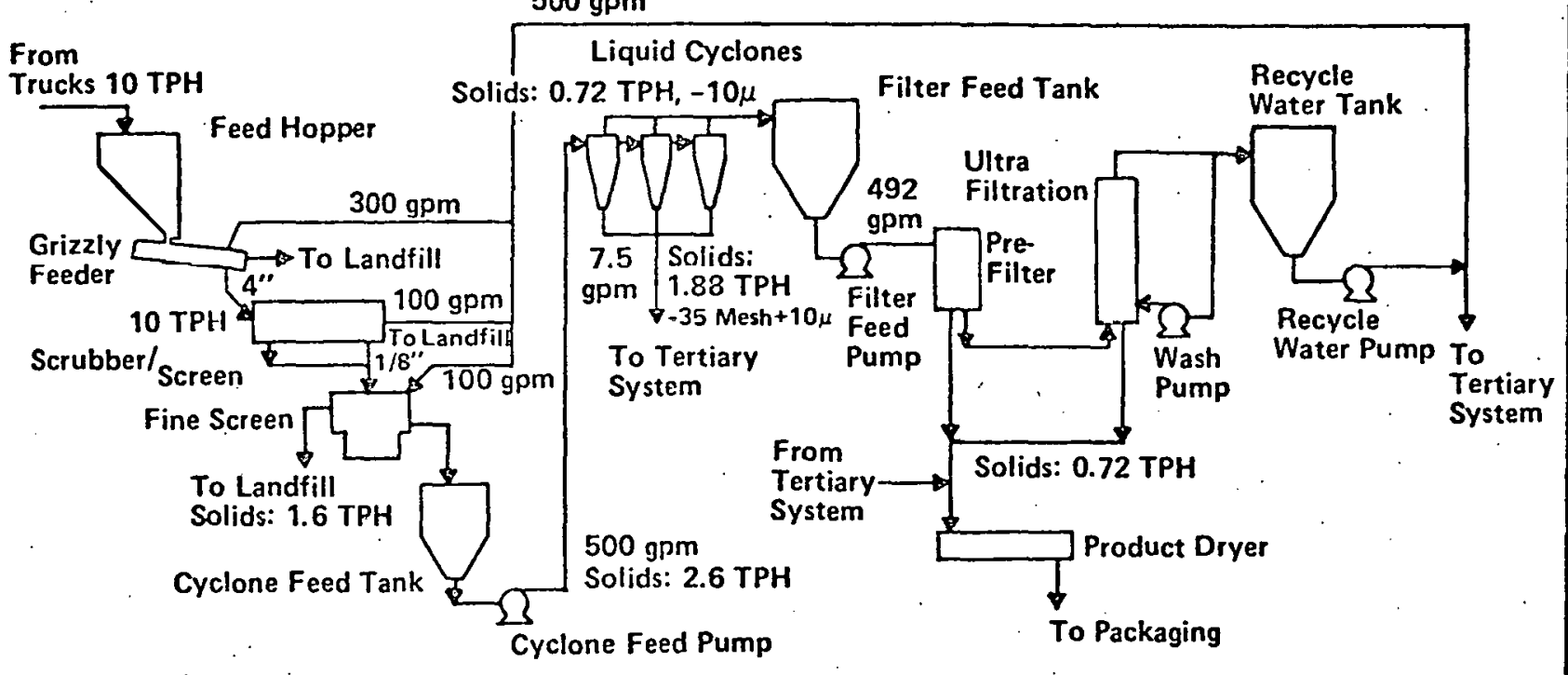

PRIMARY \& SECONDARY TREATMENT 
TABLE I

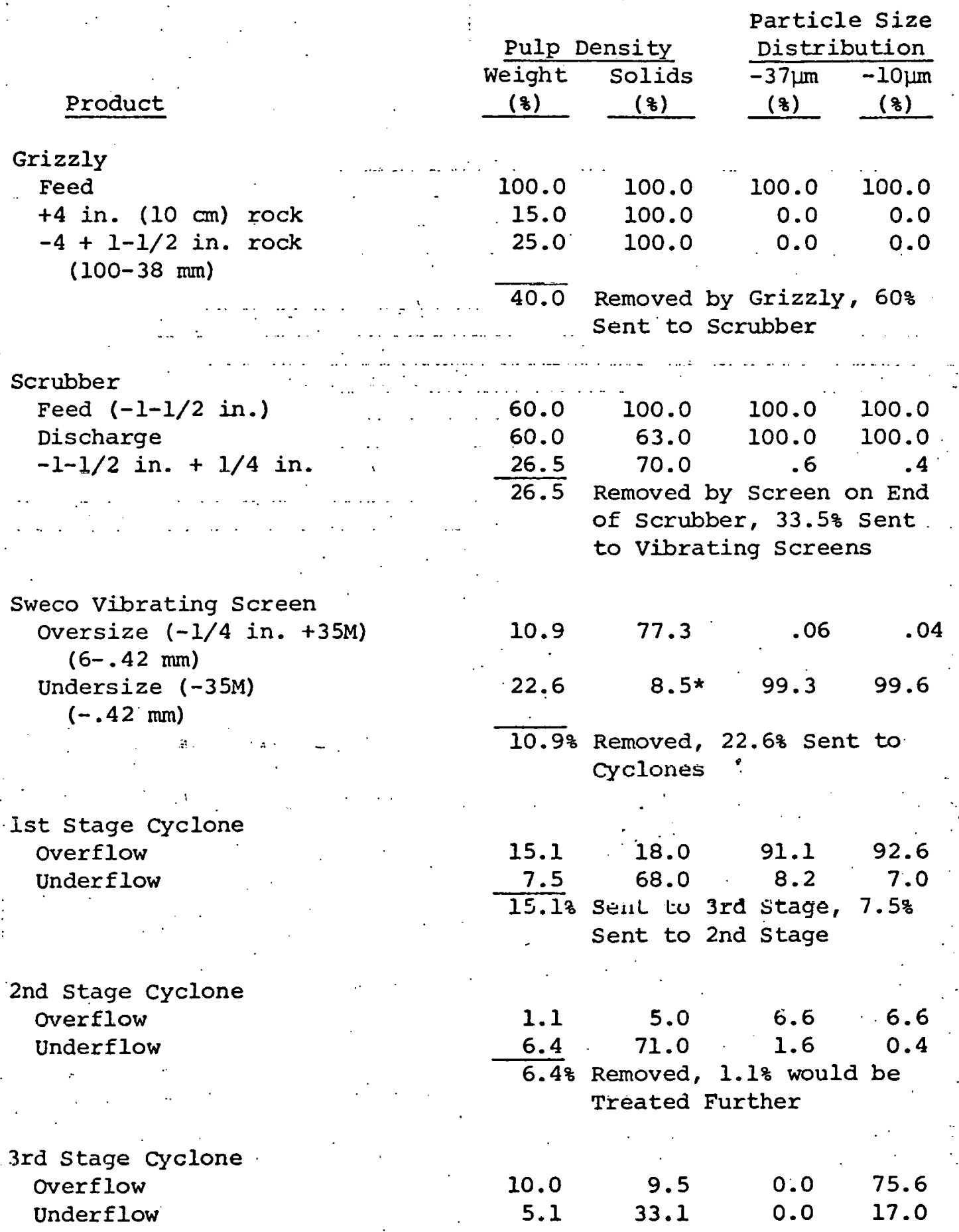

*This product was thickened to $25 \%$ solids prior to lst stage cycloning. 
the cyclones and screens could be replaced with spiral classifiers. This modification would result in a weight reduction of only 80 \% compared to $84 \%$ by the previous circuits. However, the advantages are numerous. Spiral (or screw) classifiers are almost maintenance free while cyclones are not. The spiral classifiers are also excellent dewatering devices leaving a product with a pulp density of $80 \%$ solids. Furthermore, the screen is eliminated making the circuit simpler. Spiral classifiers for a 10-ton per hour plant would have a spiral diameter of 16 inches $(400 \mathrm{~cm})$ with a total machine length of $12 \mathrm{ft}(3.6 \mathrm{~m})$. Four of these units operating in a counter-current configuration would make a very precise cut producing a clean product with a low moisture content.

Pilot plant runs based on the circuit in Figure 2 using hot soil revealed that sometimes the $-5+35$ mesh ( 4 to $0.42 \mathrm{~mm}$ ) fraction contained over $100 \mathrm{dpm} / \mathrm{g}$. This level is not acceptable. The probable cause of this situation is that the clay is lubricating the rocks in the Tromel scrubber and efficient grinding action is not being achieved. The solution is to simply deslime (remove the clay) the material prior to scrubbing. One method of achieving this removal is to have two Trommel scrubbers. The clay would be removed in the first scrubber, therefore allowing effective, scrubbing action in the second scrubber.

\section{Further Research}

Several areas need more research before final design criteria can be issued. These areas include water recycle and clay dewatering. Dissolved solids in the water must be controlled carefully if the water is to be continually recycled. The product that is to be packaged and shipped is the clay fraction. This clay is present in the water as a colloid; therefore, it must be flocculated. This flocculated clay then must be dewatered so that the volume to be shipped is minimized. Probably the best method to accompl1sh dewatering is with an automatic filter press. Such presses are relatively new, but have been shown to eliminate $20 \%$ more water than previous presses. The possibility of using a vacuum brick extruder is also being considered.

Research is also planned using the modified circuit with an acid solution. The acid solution was not selected originally because of its corrosive nature. However, tests indicate that the abrasion of the equipment by the rocks and not the corrosion by the solutions is the main factor in equipment wear.

\section{The Total concept}

As previously mentioned, the total process must be mobile so that it can be moved from site to site. Conceptual designs have been generated for mounting the process in semi-trailers. Three 


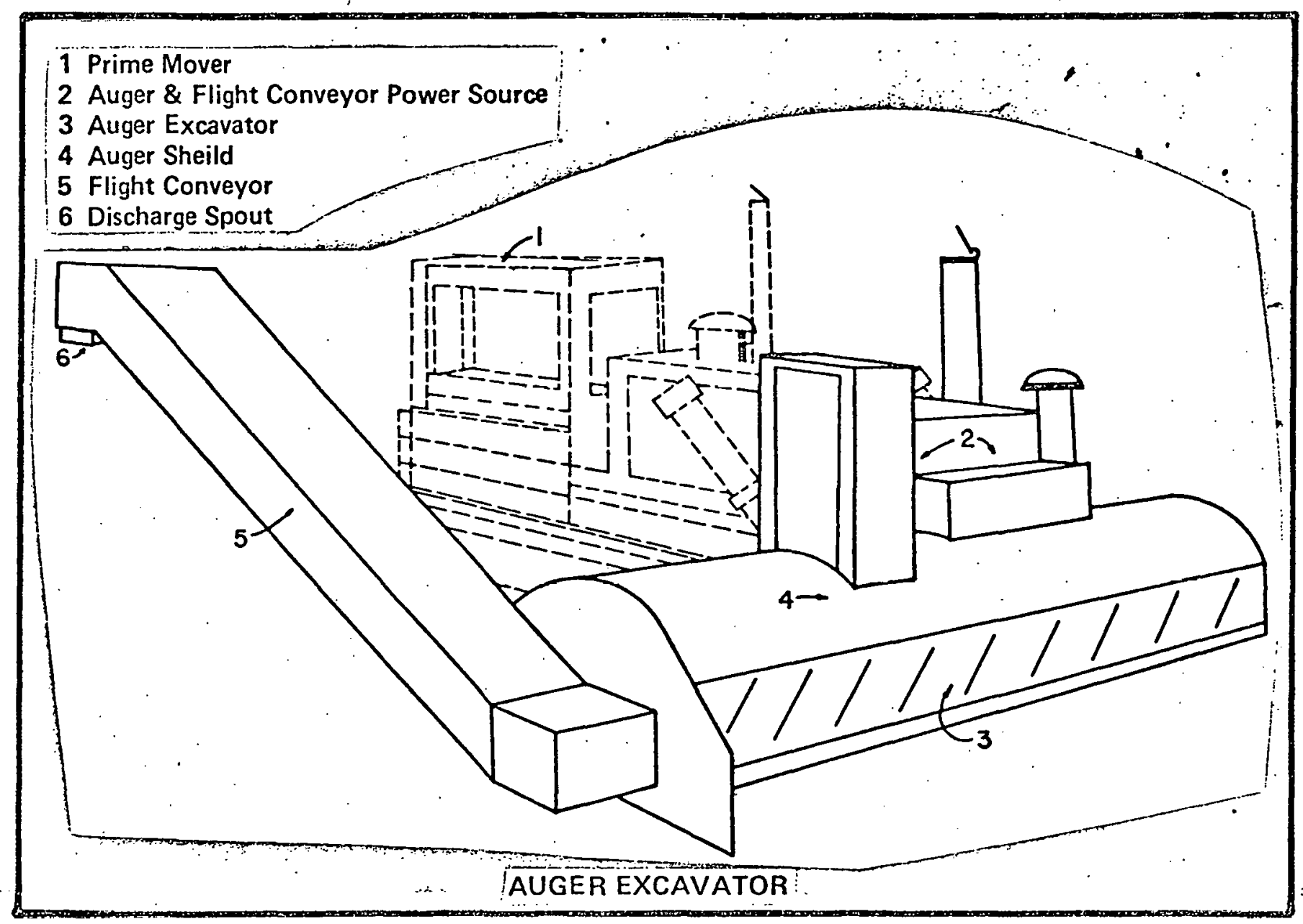


$\cdots \quad \because$

trailers will probably be required: One containing the process equipment, one with two stages of HEPA air filteration, and one with water recycle and power generation equipment.

The total concept also involves excavating the contaminated soil. To accomplish this excavation, a dustless mining machine has been conceptually designed (Figure 3 ). This machine has many advantages over the typical front-end loader method generally used. One of the main advantages is that the rotary blade is continually against the face of the excavated bank; therefore, the contaminated soil is not exposed to the open. The machine is also very maneuverable, capable of being adjusted precisely (within +2 inches). As the contaminated material is excavated, it is moved up the enclosed conveyor into a 20-ton dumpster. The dumpster is then moved to the process facility.

\section{Other DOE Sites}

Soils from four other Department of Energy sites are currently being evaluated: Hanford, INEL, LASL, and Mound. Preliminary decontamination tests are encouraging. Results will be available later this year.

\section{References}

1. C. J. Johnson, R. R. Tidball, R. C. Severson, Plutonium Hazard in Respirable Dust on the Surface of Soil, Science, $193: 488$ (1976).

2. J. A. Hayden, Size Fractionation Methods: Measuring Plutonium in Respirable Dust, Science, 202:754 (1978).

3. Draft Environmental Impact statement, Rocky Flats Plant Site, Golden, Colorado, United States Energy Research and Development Administration, ERDA-1545-D, 1977. 